University for Business and Technology in Kosovo

UBT Knowledge Center

UBT International Conference

2014 UBT International Conference

Nov 7th, 3:30 PM - 3:45 PM

\title{
Using congruence in encoding musical partituras
}

\author{
Besim Shala \\ University for Business and Technology, besimi_77@yahoo.com \\ Besiana Mehmedi \\ State University in Tetovo, besiana.mehmedi@unite.edu.mk \\ Shkodran Tolaj \\ University of Audio and Visual Arts “Esra”, shkodran.tolaj@hotmail.com \\ Azir Jusufi \\ State University in Tetovo, azir.jusufi@unite.edu.mk
}

Follow this and additional works at: https://knowledgecenter.ubt-uni.net/conference

Part of the Computer Sciences Commons

\section{Recommended Citation}

Shala, Besim; Mehmedi, Besiana; Tolaj, Shkodran; and Jusufi, Azir, "Using congruence in encoding musical partituras" (2014). UBT International Conference. 56.

https://knowledgecenter.ubt-uni.net/conference/2014/all-events/56

This Event is brought to you for free and open access by the Publication and Journals at UBT Knowledge Center. It has been accepted for inclusion in UBT International Conference by an authorized administrator of UBT Knowledge Center. For more information, please contact knowledge.center@ubt-uni.net. 


\title{
Using congruence in encoding musical partituras
}

\author{
Besim Shala ${ }^{1}$, Besiana Mehmedi ${ }^{2}$, Shkodran Tolaj ${ }^{3}$, Azir Jusufi ${ }^{1,4}$ \\ ${ }^{1}$ University for Business and Technology \\ ${ }^{2}$ State University in Tetovo \\ ${ }^{3}$ University of Audio and Visual Arts "Esra" \\ ${ }^{4}$ State University of Tetovo \\ besimi_77@yahoo.com, besiana.mehmedi@unite.edu.mk,shkodran.tolaj@hotmail.com. \\ azir.jusufi@unite.edu.mk
}

\begin{abstract}
Along with theoretical review of partituras and encryption systems, we have tried to conduct encryption of sheets by encoding all of its elements such as: encoding musical notes, encoding values of notes and intermissions, encoding accords, encoding tonalities and encoding rhythm whereby the original musical piece is transformed into an irregular and meaningless sheet. Information technology today has allowed for easier copying of authorial pieces; therefore, it is necessary to know encryption which allows protection of pieces from any misuse. Cryptology including knowledge of congruence deals with resolution of these insecurities. The significance of this paper lies in intertwining knowledge from music, math and computer sciences thus rendering our paper into an inter-disciplinary paper and we believe this will increase curiosity and the interest as well. In order to make our work more concrete, we have included encoding and decoding of a well-known melody from Shkodra"A'SAMAN TRËNDAFILI ÇELËS", whereby as encryption key we used a two-tact fragment from the song "O VENDI IM"
\end{abstract}

Keywords: pentagram, cryptosystem, encryption, decryption, music note, congruence.

\section{Knowledge on congruence and cryptosystems}

Definition 1: Let's have: $m \in \mathbb{N} . \forall a, b \in \mathbb{Z}$; Whereby $a$ is congruent with $b$ based on module $m$ then and only if $m \mid(a-b)$. We note: $a \equiv b(\bmod m)$.

or

$$
\mathbf{a} \equiv \mathbf{b}(\bmod \mathbf{m}) \Leftrightarrow \exists \mathrm{k} \in \mathrm{Z} \mid \mathrm{a}-\mathrm{b}=\mathrm{km}
$$

The congruency relation is the relation of equivalence; therefore, the meaning of congruence is closely related with the meaning of residual classes.

Definition 2: Let's have: $m \in \mathbb{N}$. Classes of equivalence defined with the relation" $\equiv$ " based on module $m$ (or as they are called in the theory of residual class numbers based on module $m$ ), they represent the union of all the numbers, which when divided with $m$ give the same residual value. Symbolically, residual classes based on module $m$ are noted as in following:

$$
K_{m}(a)=\{x \in \mathbb{Z} \mid x \equiv a(\bmod m)\} \subset \mathbb{Z}
$$

Every residual class based on module $m$ is not empty since always $\exists a \in K_{m}(a)$ whereby

$a \equiv a(\bmod m)$

Note 1: In our paper we use smallest non-negative representatives of the equivalence class.

The following serves as reminder of some congruency features: 
Theorem 1([1], p.52). If $a, b, c \in \mathbb{Z}$ and $m \in \mathbb{N}$, where by $a \equiv b(\bmod m)$, then:

1. $a+c \equiv b+c(\operatorname{modm})$

2. $a-c \equiv b-c(\operatorname{modm})$

3. $a c \equiv b c(\bmod m)$.

Theorem 2([1], p.52): If $a, b, c, d \in \mathbb{Z}$ and $m \in \mathbb{N}$, whereby $a \equiv b(\bmod m)$ and $c \equiv d(\bmod m)$, then:

1. $a+c \equiv b+d(\operatorname{modm})$

2. $a-c \equiv b-d(\operatorname{modm})$

3. $a c \equiv b d(\operatorname{modm})$.

With the use of cryptography or cryptographic systems (also cryptosystem, code), we will understand the transformation of a message called open text through encoding function (or simply encoding) whereby only one authorized receiver can return the transformed message in the initial condition.

Definition 3: Cryptosystem is called a five (P, C, K, E, D) if it meets the criteria:

$\circ \mathrm{P}$, is the final family of open texts

- $\mathrm{C}$, is the final family of encoded texts;

○ $\mathrm{K}$, space of keys, is a final family of potential keys;

$\circ$ Elements $\mathrm{E}$ andD are reflections respectively $\mathrm{P}$ into $\mathrm{C}$, of $\mathrm{C}$ into $\mathrm{P}$ whereby every $k \in K$, has an encoding rule $e_{k} \in E$ and a decoding rule $d_{k} \in D$ for

$\forall x \in P$ applies $\mathrm{d}_{\mathrm{k}}\left(\mathrm{e}_{\mathrm{k}}(\mathrm{x})\right)=\mathrm{x}$.

2 Encryption of music sheets

Taken in consider paper [2], [3], [4] and [5], we came to the following results:

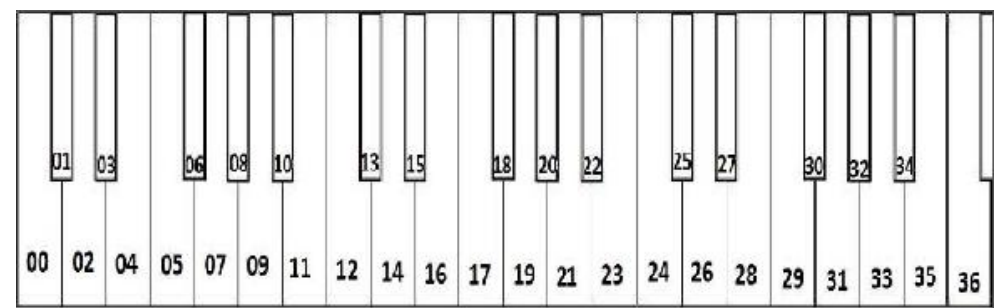

Fig. 1 Piano's keyboard

\subsection{Encryption of notes in three octaves}

(Keys in the small octave in the bass key, in the first and second octave in the violin key) 


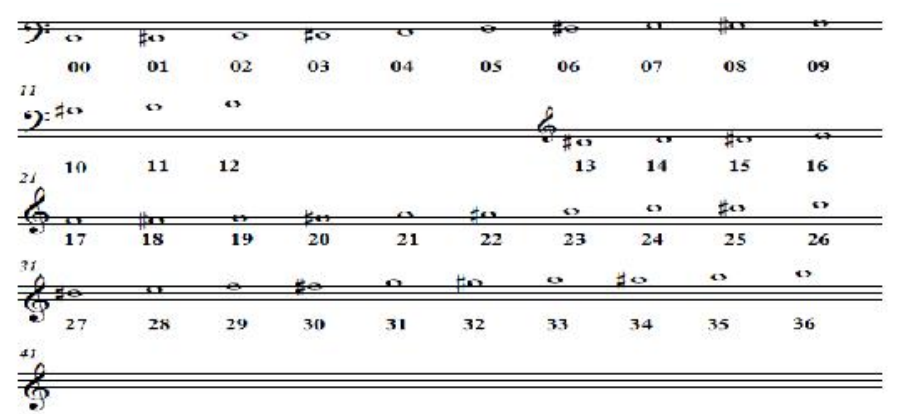

In order to encrypt notes into three octaves, we need another musical fragment, e.g. Elise

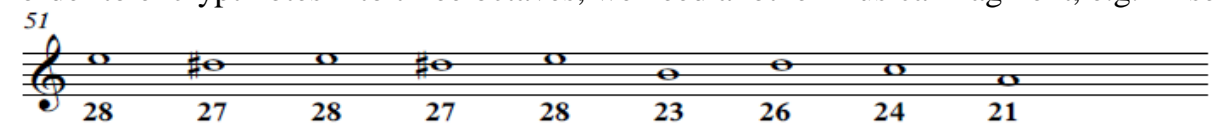

Note 2.Instead of this fragment, we can use any other musical fragment.

Encryption is as in following: $\mathrm{Np}+\mathrm{Nc}=\mathrm{Nk}(\bmod 37)$

Np means notes of the sheet we wish to encrypt; Nc means the notes of the key sheet (in our case, Elise [8]), while Nk means encrypted notes e.g. we encrypt the second octave with the help of key Elise

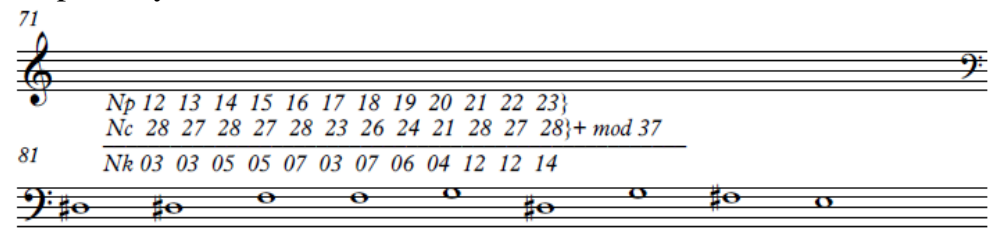

The second octave encrypted with the key Elise

Note 3. Decryption is done with

$$
\mathrm{Nk}-\mathrm{Nc}=\mathrm{Np}(\bmod 37)
$$

\subsection{Value of notes and intermissions}

(Apart from encryption of notes, values of notes and intermissions must also be encrypted)

\section{$\mathbf{O}$}

00A Full note $=4$

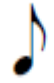

03D Eight note $=1 / 2$<smiles>[CH]1CC1</smiles>

06G Half note with dot $=3 \quad 07 \mathrm{H}$ Four note with dot $=1.5$

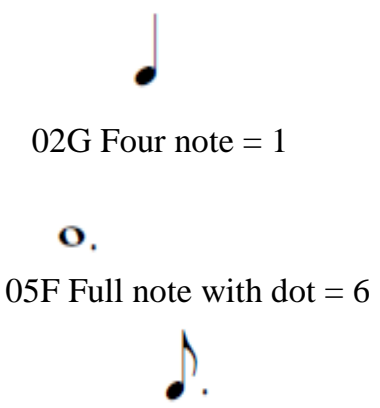

08I Eight note with dot

09L Full intermission $=4$ 10K Full intermission with dot $=211 \mathrm{~L}$ Four intermission $=1$ 
$12 \mathrm{M}$ Eight intermission=1/2 $3 \mathrm{~N}$ Full intermission with $\mathrm{dot}=614 \mathrm{O}$ Half intermission with $\mathrm{dot}=2$

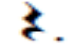

15P Four intermission with dot $=1,5$
7 .

16Q Sixteen intermission with dot $=0,75$

Note 4: Dots extend the values of notes and intermissions by half their value.

Encryption of values is done based on module 17, e.g. one tact from Elise [8]

$$
\mathrm{Vp}+\mathrm{Vc}=\mathrm{Vk}(\bmod 17)
$$

Piano
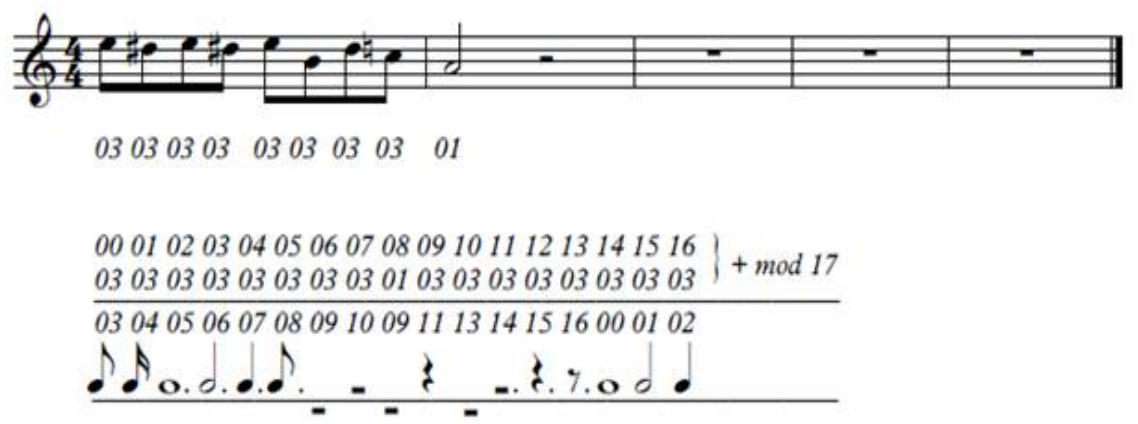

Note 5: Decryption of values will be done with

$$
\mathrm{Vk}-\mathrm{Vc}=\mathrm{Vp}(\bmod 17)
$$

Music partituras sheet, apart from notes, intermissions and their values that create the rhythm, it has the tonality, accords, the tact and a series of other composition elements. The following with introduce musical tonalities in order to encrypt the tonality.Musical tonality is the musical scale wherein the entire musical piece is developed.Tonalities are divided into Dur-Majeure or major or mol-minor or minor (with diezis and bemol) which differ greatly in sounds.

The musical tonalities are the following:

$$
\begin{aligned}
& \text { „C-Dur G-Dur D-Dur A-Dur E-Dur H-Dur Fis-Dur } \\
& \text { \# a-mol e-mol h-mol fis-mol cis-mol gis-mol dis-mol }
\end{aligned}
$$

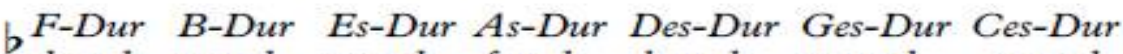

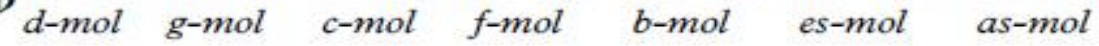

Encryption of the tonality

while decryption with

$$
\mathrm{Tp}+\mathrm{T} \mathrm{c}=\mathrm{Tk}(\bmod .28)
$$

$$
\mathrm{Tk}-\mathrm{Tc}=\mathrm{Tp}(\bmod 28)
$$




\subsection{Accords}

Main accords in a musical piece are into three grades: first grade: tonics that represents the conclusion of the musical piece; fourth grade: sub-dominant, which represents the development of the musical piece and the fifth grade - dominant, which represents the culmination of the musical piece. We will stop at the main accords which are also divided into mol and dur, major and minor. Musical sheets contain a variety of accords such as quint accord 3/5 with rotations, sextaccord 6/3 and second accord, nonarord 9. Apart from these, it is important to emphasize the musical partituras sheet and intervals. Nevertheless, we will stop only at the main quit-accords.

Encryption of accords follows

$$
\mathrm{Ap}+\mathrm{Ac}=\mathrm{Ak}(\bmod 21)
$$

while decryption is done with

$$
\mathrm{Ap}-\mathrm{Ac}=\mathrm{Ak}(\bmod 21)
$$

Note 6:Quint accord is a simultaneous sound of three sounds.

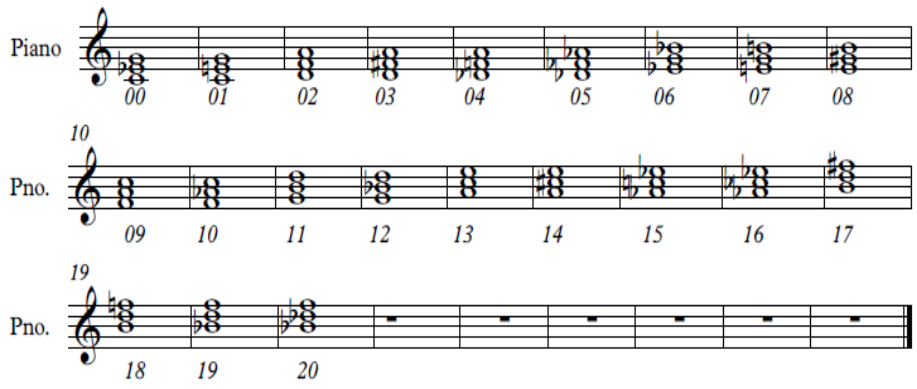

\section{Example:}

A'SAMAN TRËNDAFILI ÇELËS

(Melody from Shkodra [7], [9], [10]) 


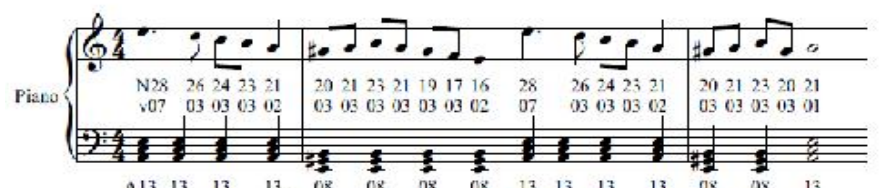

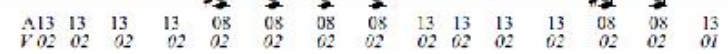
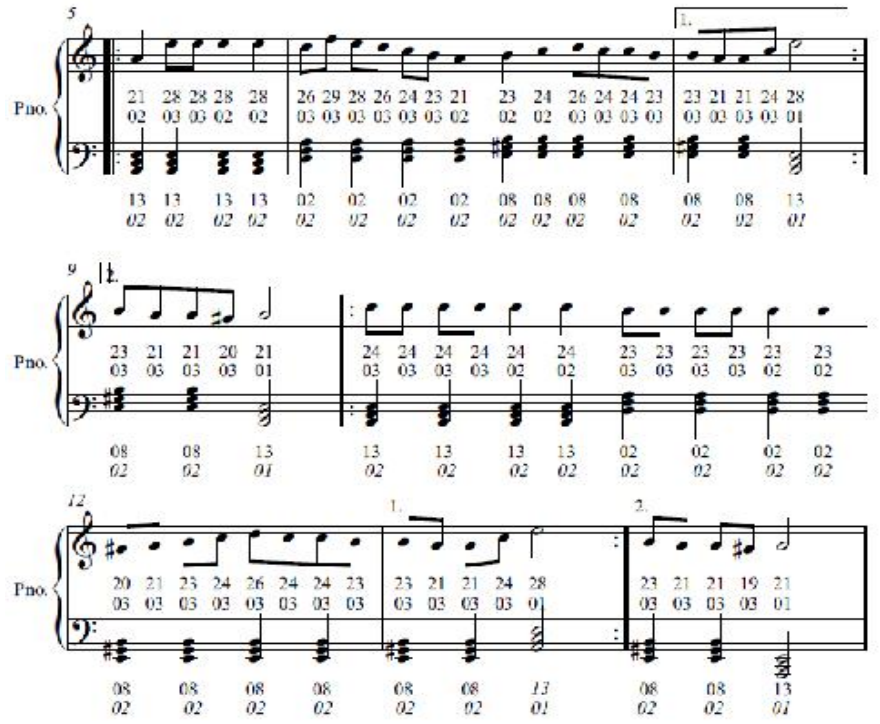

Key - O vendi im ([7], [9], [10])
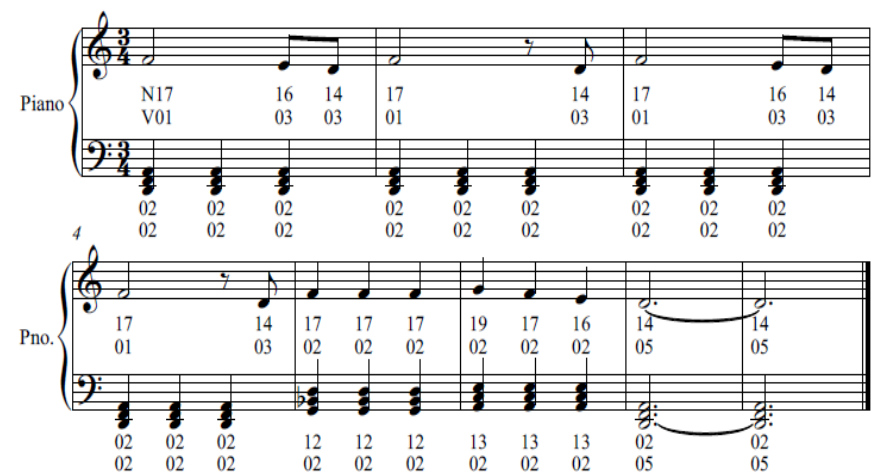

\section{Tonality encryption}

Since the musical sheet contains the tonality and the key, the encryption is simple.Main sheet is in amol (03) while the key in d-mol (21). Tonality encryption is done with module 28.

$03+21=24(\bmod 21)$

The encrypted tonality is f-mol.

\section{Rhythm}

The same method applies with rhythm as well since the entire musical sheet is in one rhythm.Main rhythms are: 2/4 (00), 3/4 (01), 4/4 (02), 5/8 (03), 6/8 (04), 7/8 (05), 9/8 (06), 12/8 (07)

Rhythm “A'saman trendafil çeles” 02 
Rhythm "O vendi im"

$02+01=03(\bmod 8)$

Encrypted rhythm is $(03)=5 / 8$.

Encryption musical note done with the help of the formula (1)

Np $\quad 28262423212021232119171628262423212021232021$

Nc + 17161417141716141714171717191716141716141714

Nk $\quad 08050103350000000133343308080402350000000035$

21282828282629282624232123242624242323212124

$+\quad 17161417141717171917161417161417141716141714$

01070508050609080804023503030304010302350101

28212828282826292826242321232426242423232121

$+17171719171614171614171417161417141717171917$

08010810080703090703040001020106010403030301

20212424242424242323232323232021232426242424

$+16141716141714171614171417171719171614171617$

36350403010401040200030003030003030303040304

242424242423232323232320212324262424232321212921

$+141717171917161417161417141716141714171717191716$

010404040603020003020000010303030401030301033600

Encryption of values and breaks done with the help of the formula (5)

\begin{tabular}{l} 
Vp 07030303020303030303030207030303020303030301 \\
Vc 01 030301120301030301120302020202020205010303 \\
\hline 08060604140604060604150509050505040508040604 \\
02030302020303030303030202020303030303030303 \\
+01120301030301120302020202020205010303011203 \\
\hline 03150603050604150605050404040508040606041506 \\
\hline 010203030202030303030303020202030303030303 \\
+010303011203020202020202050103030102030103 \\
\hline 020506041405050505050505070305060415060406 \\
\hline 0303010303030302020303030302020303030303030303 \\
+0301120302020202020501030301120301030303011203 \\
\hline 0604130605050504040508040605131506040606041506 \\
\hline 030303030301 \\
\hline 020501030301 \\
030303030103030303020203030303020203030303030303 \\
+020202020202050103030112030103030112030202020202 \\
\hline 050505050305080406050315060406050315060505050505 \\
\hline
\end{tabular}


Encryption of accorddone with the help of the formula (9)

Ap 1313131308080808131313130808131313131302020202

Act 0202020202020202020202021212121313130202020202

1515151510101010151515152020040505051504040404

080808080808131313131302020202080808080808131313

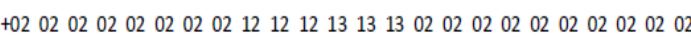

101010101010151504040415151504101010101010151515

131302020202080808080808131313131302020202080808

+02 0202121212131313020202020202020202020202021212

151504141414000000101010151515151504040404102020

08080813

$+12131313$

20000005

Encrypted partiturasisan irregular combination and in fact it does not represent anything.

\section{Encrypted Partituras}
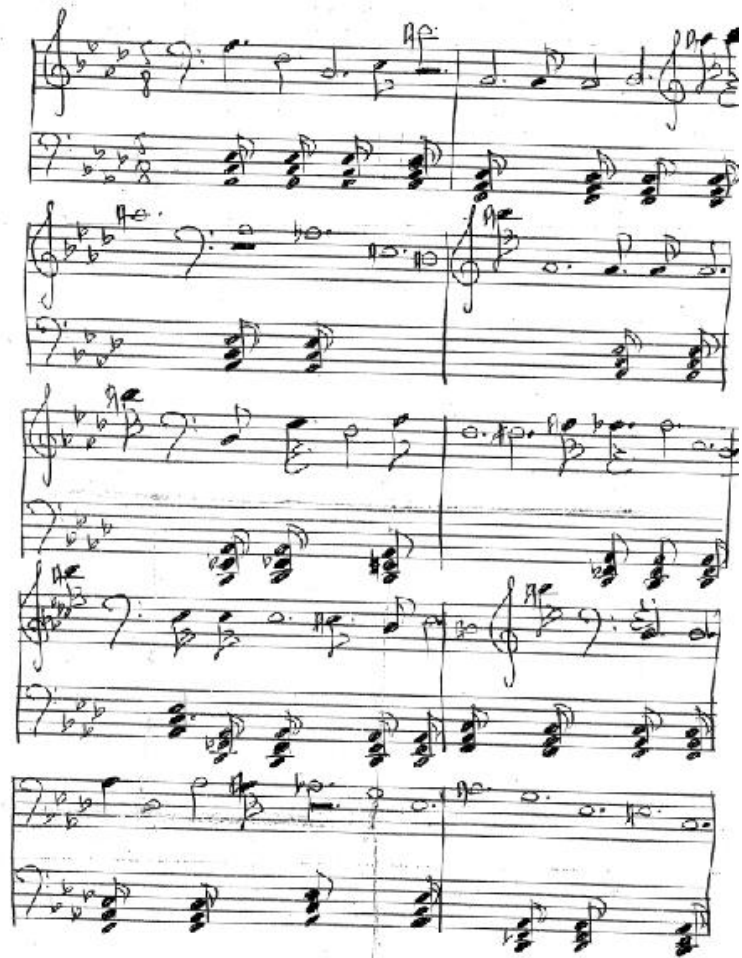


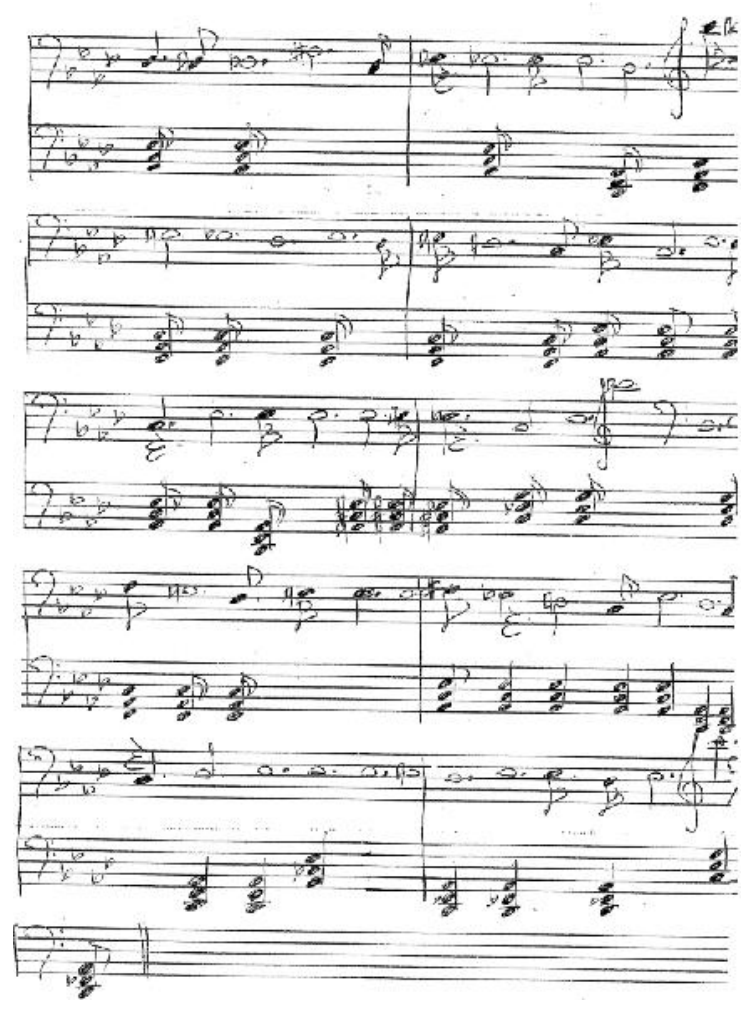

After having received the irregular sheet, the receiver deals with the following decoding whereby again as decoding key utilizing the two-tact fragment from the song "O VENDI IM"

Decryption musical notedone with the help of the formula (4)

$0805010335000000013334 \mid 330808040235$............

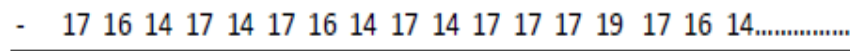

$28262423212021232119171628262423 \quad 21 \ldots \ldots \ldots \ldots \ldots \ldots \ldots . .$.

Decryption of values done with the help of the formula (6)

Vk 08060604140604060604150509050505040508040604

Vc 01030301120301030301120302020202020205010303

Vp $\begin{array}{llllllllllllllllllllll}07 & 03 & 03 & 03 & 02 & 03 & 03 & 03 & 03 & 03 & 03 & 02 & 07 & 03 & 03 & 03 & 02 & 03 & 03 & 03 & 03 & 01\end{array}$

Decryption of accord done with the help of the formula (10)

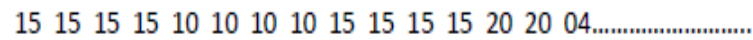

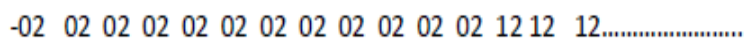

$131313130808080813131313080808 \ldots$ 


\section{Decrypted rhythm is $03-01=02(\bmod 8),(02)$ is $4 / 4$.}

Decrypted element placing in the partitures and we receive Shkodran melody "A'SAMAN TRËNDAFILI ÇELËS",

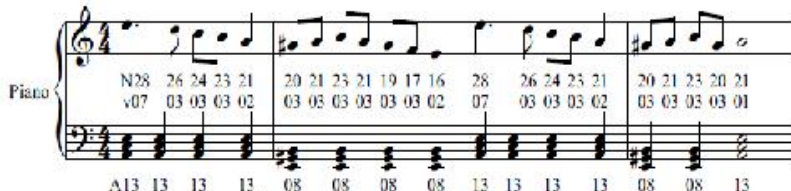

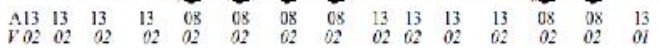
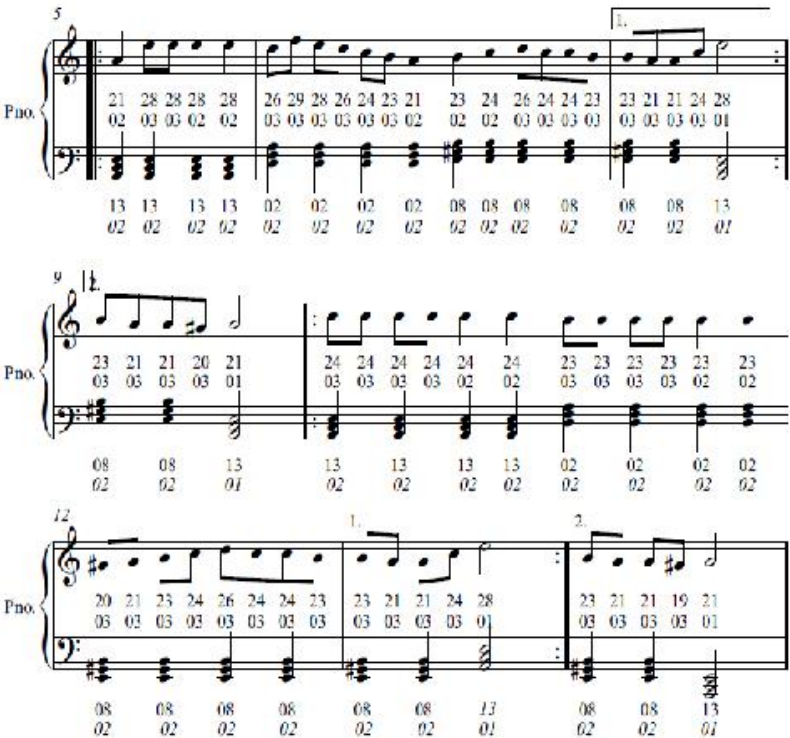

\section{References}

[1] WissamRaji, An Introductory Course in ElementaryNumber Theory, https://www.artofproblemsolving.com/.../intr..., 2014

[2] M. Yamuna, Krishna Pandey, Nikhil Choudhary, CRYPTOGRAPHY USING MUSIC NOTES, Journal of Global Research in Computer Science, Volume 4, No. 4, April 2013

[3] Sandip Dutta, Chandan Kumar, Soubhik Chakraborty, A Symmetric Key Algorithm for Cryptography using Music, International Journal of Engineering and Technology, Vol 5 No 3 JunJul 2013,

[4] Sandip Dutta Soubhik Chakraborty N.C.Mahanti, A Novel Method of Hiding Message Using Musical Notes, International Journal of Computer Applications, Volume 1 - No. 16, 2010

[5] Bruce Schneier, Applied cryptography, Wiley-India, 2007

[6] Rexhep Munishi, IDENTITETI MUZIKOR, , Prishtinë GME, 2001

[7] Rrustem Berisha, Diemensione të kenges popullore, shtypshkronja KGT, Instituti Albanologjik Prishtinë, 2011

[8] Tomor Berisha, Përmbledhje e veprave më të njohura nga Bethoven, Shtepia Botuese Rilindja, 1999

[9] Përmbledhje Këngesh Qytetare nga kompozitorë të ndryshëm, Toena Tirane, 2004

[10] Ferit Bala, Kënga dhe Këngetaret Shkodran, Shtepia Botuese, Tirane, 2014 